\title{
FREQUENCY OF IATROGENIC CHANGES CAUSED FROM OVERHANG RESTORATIONS
}

\author{
E. Boteva, D. Karayasheva and K. Peycheva \\ Department of Conservative Dentistry \\ Faculty of Dental Medicine, Medical University - Sofia, Bulgaria
}

\begin{abstract}
Summary. Overhangs from different restorations are an iatrogenic error with different results, short and long term consequences related to bone changes and periodontal diseases. Amalgam "tattoos", idiopathic subgingival hypertrophy, marginal periodontitis and bone reductions in the intradental septum are major problems. The aim of the present study is to evaluate the frequency of traumatic restorations in distal teeth and clinical criteria, related to the $x$-ray findings. Evaluating criteria, for repairing the overhangs or for replacement of the restorations, is also a goal. Three hundred and sixteen - 316 patients from both sexes, 632 dental x-rays with 948 distal teeth and 632 restorations, at least two radiographs for each patient, were analyzed. Overhangs are classified in three groups: small, middle and large. In the criteria bone changes from the overhangs are analyzed separately from the existing or nonexisting bone changes from a generalized periodontal diseases. The frequency of iatrogenic changes in this cohort group is 10.6\% from 632 restored teeth. This is a relatively small number compared with the other published studies. These overhangs are on distal teeth in sound teeth arches which makes them difficult for corrections. The evaluated criteria for replacement based on $x$-ray findings and clinical experience includes: operative and nonoperative corrections, restoration replacement, perio- and endo- therapy and follow up terms for secondary caries.
\end{abstract}

Key words: overhangs, secondary caries, iatrogenic changes

\section{BACKGROUND}

verhangs from different restorations are an iatrogenic error with different results, short- and long-term consequences related to bone changes (Hakkarainen, Ainamo 1980) and periodontal diseases (Arneberg et al. 1980, Brunsvold, Lane 1992, Kells, Linden 1992). Amalgam "tattoos", 
idiopathic subgingival hypertrophy, marginal periodontitis and bone reductions in the intra-dental septum are major problems (Bushner, Hansen 1980). The severity of the problem varies in different countries and in different dental practices. Some authors found the proportion of amalgam overhangs to be 16 to $71 \%$ of all restorations (Chan 2009).

D. C. Chan (2009) found that $57 \%$ have at least one filling with overhang, $27 \%$ three or more, in $235 \mathrm{x}$-rays with 1,787 proximal restorations. N. Wilson (1997) describes $60 \%$ overhangs in 2,379 fillings. Variable criteria for replacement (Gordon at al. 2006) are applied in different articles: secondary caries, proximal contacts, post-operative sensitivity, pain and marginal periodontitis. Treatment methodology varies too: from manual intra-dental polishing and ultrasound adjusting to diamond burs reduction and restoration replacement and is related to the clinical quality of the restorations (Skogedal, Heloe 1979).

Different methods are used in the studies from their beginning, from mostly x-rays (Coxhed et al. 1978) to scanning electron microscopy (Opdam et al. 1998).

There are several unclear topics about this matter, because practically replacing fillings in most cases is the preferable approach for many dentists, due to financial matters. On the other hand this causes every time preparation of more and more sound enamel and dentin.

\section{AIMS}

1. The aim of the present study is to evaluate the frequency of traumatic restorations in distal teeth and clinical criteria, related to x-ray findings.

2. To evaluate criteria, for repairing the overhangs or for replacement of the restorations.

3. To focus the attention on this matter for better preventive restoration technology.

\section{MATERIAL AND METHODS}

Patients: A cohort group of 316 patients (from both sexes) treated in the Department of Conservative Dentistry in Sofia between 2007 and 2012 took part in the study. Dental x-rays with premolars and molars, with 948 distal teeth; teeth 4 to $7 \mathrm{n}$ $=213$ or 5 to $8 \mathrm{n}=103$, with 632 restorations were evaluated. Two radiographs for each patient were analyzed from one examiner in two different occasions with at least one month between them. Left and right teeth, upper and lower and vital and non-vital, were not placed in different groups as this is not related in any way to the purpose of the study.

$X$-rays: Dental segment Dick X-rays were selected according to the following criteria: on each radiograph at least three teeth to be present with at least two fillings $(n=632)$ and all to be analyzed under magnification $\times 5$. According to the size of the overhang and to the detected pathology the restored teeth were placed in six 
groups: small, middle, large and in each one of them two subgroups were formed with and without changes in the interdental septum of the bone $[4,6]$.

Protocol: As small restorations were classified those one, with radiographic images and appearance like small sharp angle $1 \mathrm{~mm}$ from the approximal gingival margin. When probed the margins were sharp, not smooth and there was no bleeding at all. Patients had no complains and if they had it was occasional discomfort. Middle sized overhangs were appeared like excessive material bellow and under the intradental papilla, into part of the intradental space and bigger than $1 \mathrm{~mm}$. After probing there was bleeding. Patients complaints varied due to the type of the restorations, occlusion and individual sensitivity. The last group were fillings with large overhang, which fills the whole intradental space and is bigger than $3 \mathrm{~mm}$. Bleeding occurred even without probing and often there was a gap between the restoration and the tooth. Probation led to excessive bleeding. Always there were complaints and often periodontal abscesses were present. In the second and third types horizontal percussion was positive.

The bone changes from the overhangs were analyzed separately from the existing bone changes as a result of generalized periodontal diseases.

All patients are signing a consent form, approved from the ethical committee.

Exclusion criteria: less than three teeth in the distal area, less than $2 \mathrm{x}$-rays per patient, less than two restorations and radiographs with very poor quality.

Statistics: Table and graphic analysis were used for the study.

All the radiographs used, were not taken for the purposes of this study. These $x$-rays were taken for the aims and tasks of endodontic treatments or biological treatments of the pulp.

\section{RESULTS}

At least 3 teeth in one $x$-ray with 2 restorations medial and distal neighbors were present, due to the fact that all corrections were easier when teeth were less, towards the missing tooth only if secondary caries did not exist. That was the reason the criteria to include intact distal fragments for better evaluation of clinical reasons and techniques, for repairing overhangs or for replacement of restorations.

Table 1. Types of detected overhangs $(n=67)$ on 632 teeth with restorations $-10.6 \%$

\begin{tabular}{|l|c|c|c|c|c|c|}
\hline Groups & \multicolumn{2}{|c|}{ Small } & \multicolumn{2}{c|}{ Middle } & \multicolumn{2}{c|}{ Large } \\
\hline Bone changes & None & Present & None & Present & S & Present \\
\hline Teeth 4-7 & 12 & 9 & 1 & 12 & - & 7 \\
\hline Teeth 5-8 & 8 & 4 & 1 & 6 & - & 7 \\
\hline Total & 20 & 13 & 2 & 18 & - & 14 \\
\hline
\end{tabular}




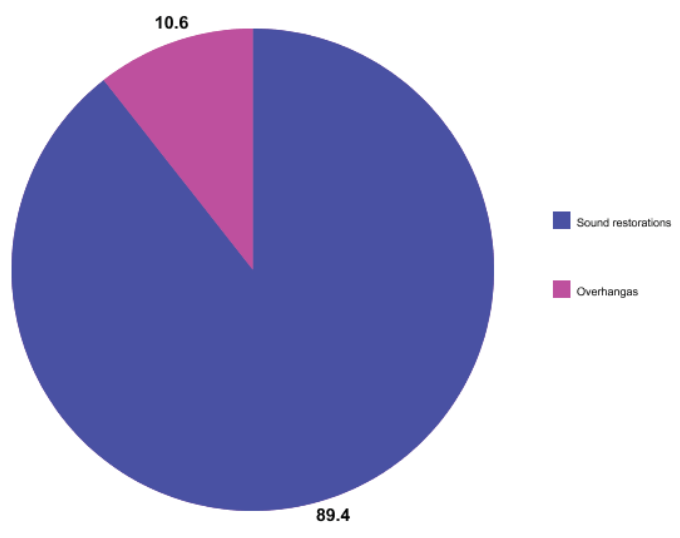

Fig. 1. Proportion of the overhangs from the data shown in table 1

Under the conditions of this study large overhangs without changes in the bone were not found. Small overhangs without changes in the bone were a great proportion of $30 \%$ from all 67 overhangs $-10.6 \%$ of all restorations. Changes in the bone were observed in $67.2 \%$ from all found overhangs and $7.1 \%$ from all the fillings in the distal area.
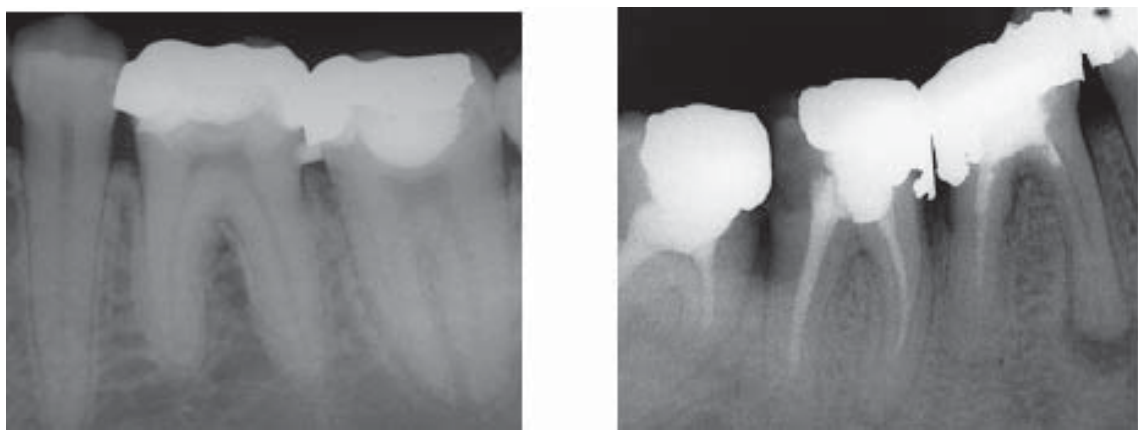

Fig. 2. X-rays of small overhangs with (a) and without (b) bone changes
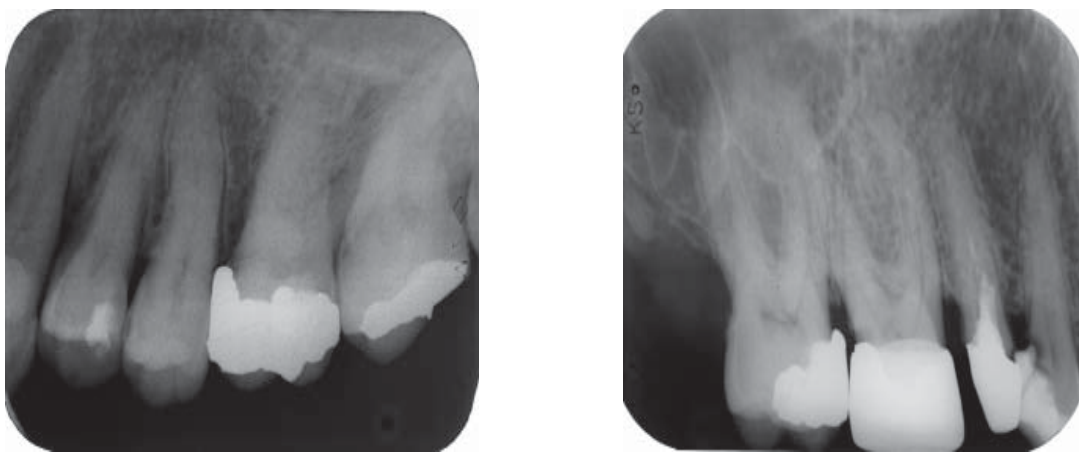

Fig. 3. X-rays of middle overhangs with (a) and without (b) bone changes 

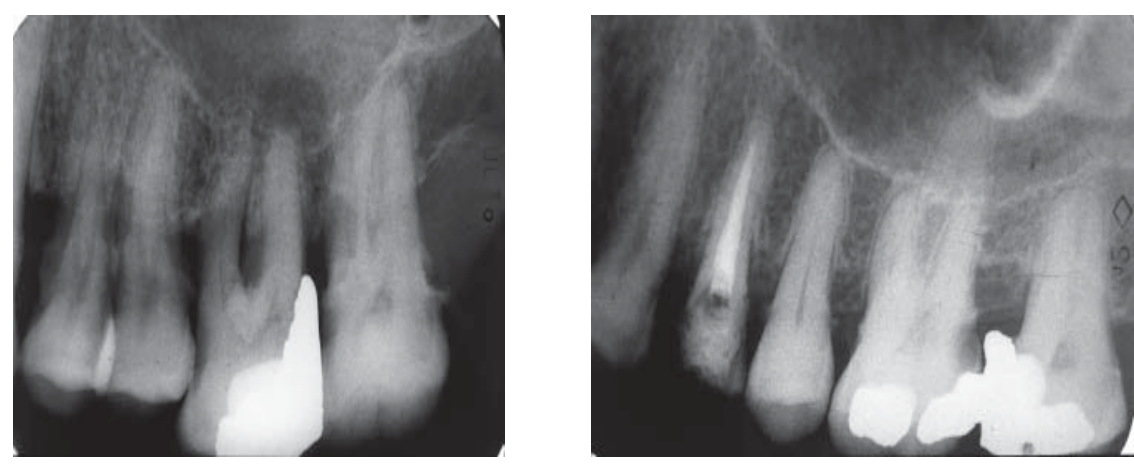

Fig. 4. X-rays of large overhangs with bone changes

\section{DISCUSSION}

Thirty three $-5.2 \%$ of all the restorations in the distal area needed replacement, because $49.3 \%$ of all overhangs were small, which could be drilled out after pin or orthodontic disk separation from the neighbor tooth. An individual approach was recommended in very small number of cases: middle overhangs without bone changes, only $0.3 \%$ of all distal restorations and $3 \%$ of all overhangs. The findings were very encouraging compared with some data from the UK, showing up to 60\%, USA - 48\% and from Norway - 32\%, overhangs and secondary caries (Wilson, Burke, Mjor 1997).

Middle and large overhangs with bone changes were a proportion of $5 \%$ of all restorations, which needs replacement and $50 \%$ of all overhangs. Half of them needed periodontal treatment of pockets, restorations replacement and multiple steps treatment. Thirty three, $5.2 \%$ of the restorations in the distal area needed replacement, This type of iatrogenic errors can also be corrected with ultra sound, disks or bands, but the risk of cracks in the borders of the restoration always persists. An individual approach was recommended in very small number of cases: middle overhangs without bone changes, only $0.3 \%$ of all distal restorations and $3 \%$ of all overhangs.

Applying a reasonable clinical criteria for correction of overhangs could be an operative correction of all small and middle without bone changes overhangs shown on fig. 1(a, b) and 2(b). The corrected restorations needed a follow up for 1 year (two clinical exams every 6 months) for secondary caries. Fillings shown in figures 2(a) and figure 3 , needed operative changes of the respective restoration, replacement and some of them periodontal pockets treatment. Further endodontic treatments were also possible and in very rare clinical conditions there was a need of combination of both treatment methods.

\section{CONCLUSIONS}

The frequency of iatrogenic changes in a cohort group of 316 patients was $10.6 \%$ from 632 restored teeth. This is a relatively small number compared with other published studies. 
1. Even small overhangs (more than one third of them) can lead to bone changes with damages of the intradental septum.

2. The observed overhangs were on distal teeth in sound teeth arches which makes them difficult for corrections without total replacement of the restorations.

3. The evaluated criteria for replacement based on x-ray findings and clinical experience included: operative and non operative corrections, restoration replacement, perio- and endo- therapy and follow up terms for secondary caries.

\section{REFERENCES:}

1. Arneberg, P., Silness J., Nordbo H. Marginal fit and cervical extend of Class II amalgam restorations related to periodontal condition. - J of Period. Res. 1980, 15, 6, 669-677.

2. Brunsvold, M.A., Lane J.J. The prevalence of overhanging dental restorations and their relationship to periodontal disease. - J of Clin. Pharm. and Therap. 1992, 17, 2, 67-72.

3. Bushner, A., Hansen L.S. Amalgam pigmentation (amalgam tattoo) of oral mucosa: A clinicopathologic study of 268 cases. - Oral Surg., Oral Med., and Oral Pathol. 1980, 49, 2, 139-147.

4. Chan, D.C., Chung A.H. Management of Idiopathic subgingival amalgam hypertrophy. - The common amalgam overhang. - Oper. Dent., 2009, 34,6,753-758.

5. Coxhead, L.J., Robertson J.B., Simpson E.F. Amalgam overhangs: A radiographic study. - New Zealand Dent J 1978, 74, 337, 145-147.

6. Gordan, V.V., Railey G.L., Blaser P.K., Mjor I.A. Two year clinical evaluation of alternative treatments to replacement of defective amalgam restorations. - Oper. Dent. 2006, 31, 4, 418-425.

7. Hakkarainen, K., Ainamo J. Influence of overhanging posterior root restorations on alveolar bone height in adults. - J. Clin. Periodontol. 1980, 7, 2, 114-120.

8. Kells, B.E., Linden G.J. Overhanging amalgam restorations in young adults attending a periodontal department. - J of Dentistry 1992, 20, 2 85-88.

9. Opdam, N.J., Roeters F.J., Feileer A.J., Smale I. A radiographic and scanning electron microscopic study of a proximal margins of a Class II resin composite restoration placed in vivo. - J Dent. 1998, $26,4,319-327$.

10. Skogedal, O., Heloe L.A. Clinical quality of amalgam restorations. - Scand J Dent Res 1979, 87, 6, 459-461.

11. Wilson, N.H., Burke F.J., Mjor I.A. Reasons for placement and replacement of restorations of direct restorative materials by a selected group of practitioners in the UK. - Quintessence Int. 1997, 28, 4, 245-248.

\section{Corresponding author:}

E. Boteva

Department of Conservative Dentistry

Faculty of Dental Medicine

1 Sv. G. Sofiiski St

BG - 1431 Sofia

E-mail: e_boteva@abv.bg 